\section{Did the subjects and the controls have the same disease?}

The article by Roberts et $a l^{1}$ is important because it points to potential occurrence of side effects due to paracetamol, some of which are life-threatening. However, we have some doubts about the conclusions because it is not certain that they really show the responsibility of the drug itself in the adverse events mentioned. Although the authors well define methodological limitations of the article, we think that they didn't take into account the main confounding factor.

The major confounding factor seems to be the reason of paracetamol use, since it is important to know whether the disease treated in the controls is similar to the one in subjects.

When rheumatic diseases are considered, we know that in rheumatoid arthritis, cardiovascular morbidity is higher than in general population, related to the disease activity. ${ }^{2}$ In osteoarthritis, where long-term paracetamol use is commonly prescribed, the disease is usually associated with metabolic syndrome and decreased physical activity that lead to increased cardiovascular morbidity. ${ }^{3}$ In a later article, it seems essential to have a more accurate assessment of the comparability of the groups in terms of risk factors.

Romain J Forestier, ${ }^{1}$ Fatma Begum Erol Forestier ${ }^{2}$

${ }^{1}$ Centre de Recherche Rhumatologique et Thermal, Aix-Les-Bains, France
${ }^{2}$ Istanbul Physical Therapy Rehabilitation Training and Research Hospital, Istanbul, Turkey

Correspondence to Dr Romain J Forestier, Centre de Recherche Rhumatologique et Thermal, Aix-Les-Bains 73100, France; romain.forestier@wanadoo.fr

Competing interests None declared.

Provenance and peer review Not commissioned; internally peer reviewed.

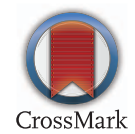

To cite Forestier RJ, Erol Forestier FB. Ann Rheum Dis 2016;75:e43.

Received 30 March 2015

Accepted 30 March 2015

Published Online First 20 April 2015

Ann Rheum Dis 2016;75:e43. doi:10.1136/annrheumdis-2015-207692

\section{REFERENCES}

1 Roberts E, Delgado Nunes V, Buckner S, et al. Paracetamol: not as safe as we thought? A systematic literature review of observational studies. Ann Rheum Dis 2016;75:552-9.

2 Solomon DH, Kremer J, Curtis JR, et al. Explaining the cardiovascular risk associated with rheumatoid arthritis: traditional risk factors versus markers of rheumatoid arthritis severity. Ann Rheum Dis 2010;69:1920-5.

3 Liu SH, Waring ME, Eaton CB, et al. Association of objectively measured physical activity and metabolic syndrome among U.S. adults with osteoarthritis. Arthritis Care Res (Hoboken) 2015. doi:10.1002/acr.22587 